\title{
PRESSURE ANALYSIS AND SPATIAL QUANTITATIVE ASSESSMENT OF IMPACT OF HUMAN ACTIVITIES ON LAGOON ECOSYSTEM: A CASE STUDY IN XINCUN AND LI'AN LAGOONS, HAINAN, CHINA
}

\author{
FANG, X. ${ }^{1,2}-$ HAO, C. L. ${ }^{1}-$ CHENG, C. G. ${ }^{1}-$ NI, W. ${ }^{1}-$ WANG, J. C. ${ }^{1}-$ ZHANG, Y. F. ${ }^{1 *}$ \\ ${ }^{1}$ The Second Institute of Oceanography, State Oceanic Administration \\ 36 BaochubeiLu Rd., Hangzhou 310012, P. R. China \\ (phone: +86-571-8196-3336; fax: +86-571-8805-4750) \\ ${ }^{2}$ Nanjing University, No. 22 Hankou Rd., Gulou District, Nanjing, Jiangsu 210093, P. R. China \\ *Corresponding author \\ e-mail: zhangyf123@163.com \\ (Received $25^{\text {th }}$ May 2018; accepted $31^{\text {st }}$ Aug 2018)
}

\begin{abstract}
Compared to bays, coastal lagoons are more vulnerable to the effects of human activities. The continued deterioration of the Xincun and Li'an Lagoon ecosystems has affected habitat health in the region; therefore, the State Oceanic Administration has proposed the "Blue Bay Remediation Action Plan". To formulate a comprehensive, evidence-based remediation plan, a comprehensive assessment of ecosystem pressure that includes a quantitative spatial study of the cumulative impact intensity of human activities was conducted in the study region. The results showed that the Xincun Lagoon ecosystem pressure composite values have gradually decreased since 2012. Additionally, the area of extremely strong human activities accounted for only $6.67 \%$ of the sea area, most of which was distributed at the mouth of the lagoon. However, the ecosystem pressure composite value of the Li'an Lagoon continued to grow until 2014, at which time the area of extremely strong human activities accounted for $13.53 \%$ of the sea area, primarily in the Li'an town center region.
\end{abstract}

Keywords: human activities, eco-environmental stress, impact assessment, spatial quantization, $P-S-R$ model, coastal lagoons ecosystem

\section{Introduction}

Coastal lagoons occupy $13 \%$ of the world coastline (Ana et al., 2018). Compared with bays, coastal lagoons are more actively affected by interactions between land, marine, and atmospheric processes and their environments and ecosystems are more prone to the dual effects of land and sea. Coastal lagoons are also more sensitive to fluctuations caused by changes in various natural processes and human activities, and their ecosystems are particularly vulnerable.

The deterioration of the ecosystems of the Xincun and Li'an Lagoons has affected many habitats (including coral reefs, mangrove forests, and seagrass beds) in the region. According to relevant data and preliminary surveys, large patches of coral reefs are no longer alive, and mangrove habitats are fragmented in the study site. Seagrass beds in the region have also exhibited reduced area and abundance and increased pollutants attached to seagrass.

In 2016, the State Oceanic Administration proposed the "Blue Bay Remediation Action Plan" to improve marine environmental quality, as well as coastal, marine and island ecosystem functions, and to protect marine ecological security. To formulate a scientific and comprehensive remediation plan, it is necessary to conduct a preliminary 
survey and analysis of relevant pressure factors of the Xincun Lagoon ecosystem, diagnose the impact of pressure factors on the lagoon ecosystem, and propose a comprehensive remediation target system and measures for ecosystem conservation and utilization.

The academic community has conducted research into and put forward some indicators and methods for quantitative evaluation of ecosystem pressure. These include ecological footprint analysis (Leo et al., 2014), the green accounting method (Bartelmus, 1999), energy analysis (Brown and Ulgiat, 1991), the environment quality index (Cui and Li, 2014), pollutant emissions indicators, system dynamics (Château et al., 2015), input-output methods, and multivariate statistical analysis. These methods have made positive contributions to efforts to assess the power of economic development to the ecosystem, but there are still some problems. For example, the ecological footprint analysis method describes very little about the pressure from environmental pollution. The environmental quality method and the pollutant emission indicator method cannot describe the pressure caused by ecological damage, so they are not sufficiently comprehensive; the green nuclear algorithm and the energy (value) analysis method represent environmental pollution and ecological damage in the form of currency and energy, respectively, but they are not sufficiently reliable in terms of quantification; the system dynamics, input-output, and multivariate statistical methods are reasonably comprehensive and take into account more factors, but their calculation processes are more complicated than those of other methods, and the results are not intuitive.

In addition, the study of the cumulative impact of human activities has proceeded tortuously. Since the 1970s, the academic community has used environmental sensitivity indicators to identify marine areas sensitive and susceptible to human activities (Gundlach et al., 1978). In the late 1990s, scholars began to evaluate the cumulative effects of multiple pressures (Wiegers et al., 1998). But it was not until 2008 when Halpern et al. selected 17 human activities for the global marine ecosystem, quantified their cumulative impact on global marine ecosystem, and mapped out cumulative impact increments (Halpern et al., 2008), that related studies began to spring up like bamboo shoots after rain. Since then, the field has rapidly developed and gradually become one of the hotspots of basic research in marine spatial planning (MSP). According to a literature review analysis (Korpinen et al., 2016), the research method reported by Halpern et al. was used directly or indirectly in more than half of the papers in the relevant field (Micheli et al., 2013; Marcotte et al., 2015). Compared with the earlier methods, Halpern et al. combined and quantified human activity pressure with ecosystem state (simplified to a linear relationship), so that the research method forms a standardized model, and the results can be compared globally.

\section{Preparation}

\section{Conceptual framework}

This study aimed to combine data describing the current status of human activities (pressure) and ecosystem condition (state) in the study site and propose corresponding remediation measures (response). This process meets the definition of the pressurestate-response (PSR) framework.

The PSR framework was first proposed by Friends and Rapport (Friends and Rapport, 1979) to analyze the relationship between pressure, current state, and response 
in natural environments (Xu et al., 2017). In the 1970s, the Organization for Economic Co-operation and Development revised the PSR model and applied it to environmental studies. In the early 1990s, the OECD conducted applicability and efficacy analysis of the PSR model when used in analysis and studies of important ecosystem-associated indicators. Because the PSR model has an extremely clear causal relationship, it is widely used in studies of marine ecosystems and evaluation of wetland and lake resources.

\section{Study region and area}

The study site is located in the southeast portion of Lingshui Li Autonomous County, which is located on the southeast coast of Hainan Island, China (N18 $22^{\prime}-18^{\circ} 47^{\prime}$, E $\left.109^{\circ} 45^{\prime}-110^{\circ} 08^{\prime}\right)$. This site is a classical tide-controlled natural lagoon composed of two lakes separated by a shoal in the middle. The southern portion of the study site is bounded by Nanwan Monkey Island and Niubai Mountain as natural barriers to the South China Sea. The waves are gentle in the lake, and the twin lakes are connected by the South China Sea through narrow mouths (Fig. 1).

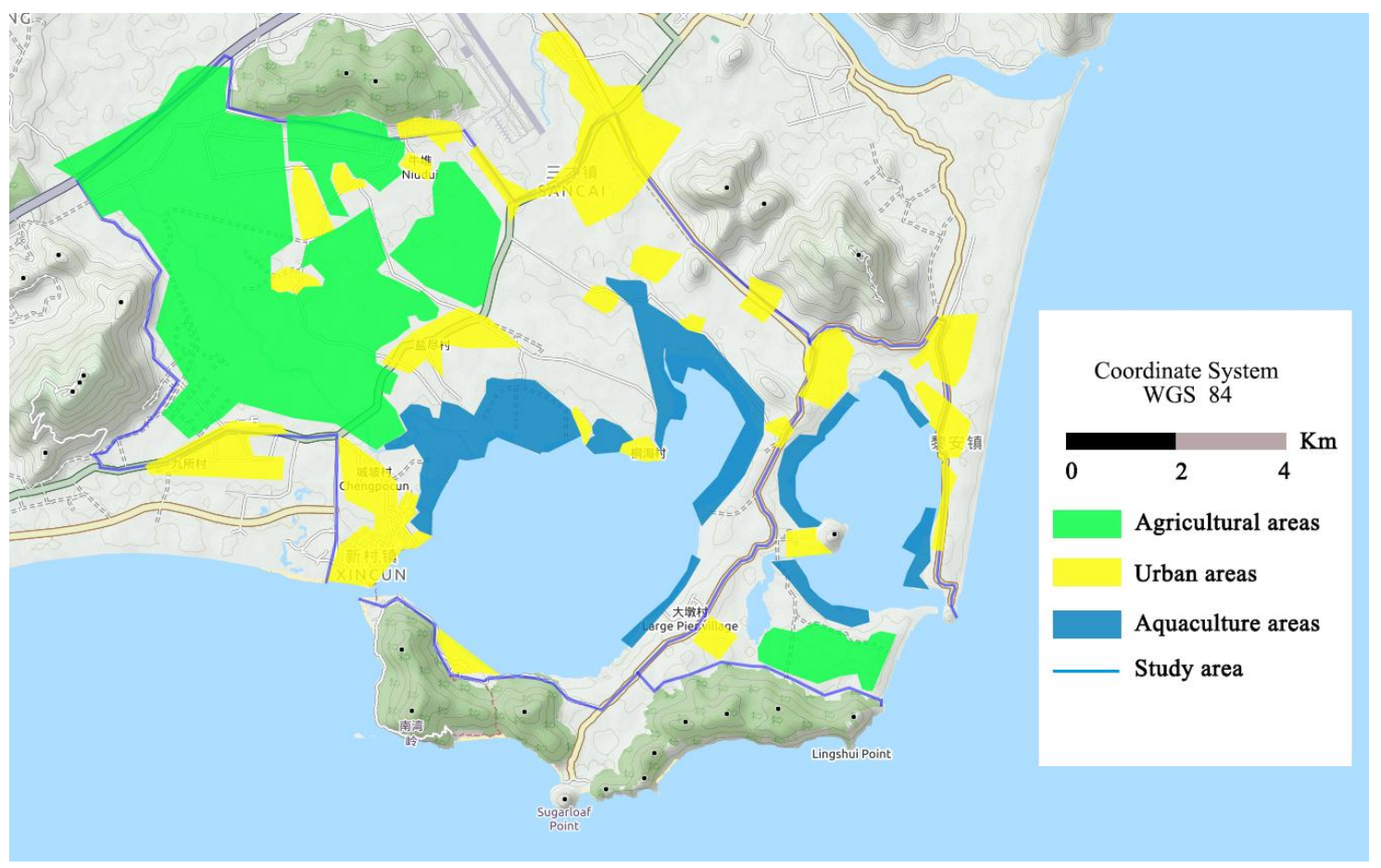

Figure 1. Map of study region and area

Lagoon pollution originates from water bodies, but land is also a major pollution source; therefore, water and land regions were included when determining the study site. The water region refers to regions that are formed by the water that curves inwards. The delineation of the land region boundary was based on an enclosed area formed by the watershed in the lagoon and the coastline of the lagoon.

However, for a large drainage basin, if the entire basin cannot be traced during estimation, tracing can be conducted to the part which is below the controlled section of the basin (i.e., the drainage basin only includes the region below the controlled section), 
while that in upstream region will be estimated by using monitoring data for the controlled section. Therefore, the study area for this investigation was the water catchment area of the Qugang and Qugou rivers and their tributaries, which are bound by the G98 Hainan Island Ring Expressway, the China National Highway 223 and the surrounding mountains (region enclosed by the blue line in Figure 1.

\section{Methods}

\section{Comprehensive assessment of lagoon ecosystem pressure}

So far, there have been few studies on the evaluation of lagoon ecosystem pressure, and there is currently no standard evaluation indicator or method. We here report an optimized method on the basis of the Eco-environmental Stress Index (ESI) method proposed by $\mathrm{Xu}$ et al. (2004) of Peking University, rendering it able to adapt to the actual situation of the lagoon. This method has been validated in terrestrial areas (Hao et al., 2012; Song et al., 2014) and is a relatively new method that can intuitively indicate the pressure of socio-economic development on ecosystems and the change trend of the pressure.

This study analyzed the major stress factors of lagoon ecosystems to design an evaluation indicator system and then applied this system to the evaluation of the lagoon ecosystem. The specific evaluation steps were as follows: (i) determination of evaluation indicators and selection of year limit for evaluation; (ii) data standardization; (iii) determination of weight values; (iv) calculation of ecosystem pressure index.

Step i: We selected representative indicators (Table 1) based on the current status of the ecosystem in the study site for an evaluation period of 2011 to 2015.

Table 1. Pressure evaluation indicator system for Xincun and Li'an Lagoon ecosystems

\begin{tabular}{|c|c|c|c|c|c|c|c|}
\hline \multicolumn{2}{|l|}{ Layer A } & \multicolumn{2}{|l|}{ Layer B } & \multicolumn{2}{|l|}{ Layer C } & \multicolumn{2}{|l|}{ Layer D } \\
\hline \multirow{2}{*}{$\begin{array}{l}\text { Population } \\
\text { pressure }\end{array}$} & \multirow{2}{*}{$A_{1}$} & $\begin{array}{l}\text { Population } \\
\text { density }\end{array}$ & $B_{1}$ & & & & \\
\hline & & $\begin{array}{l}\text { Population } \\
\text { growth rate }\end{array}$ & $B_{2}$ & & & & \\
\hline \multirow{2}{*}{$\begin{array}{l}\text { Economic } \\
\text { pressure }\end{array}$} & \multirow{2}{*}{$A_{2}$} & GDP per capita & $B_{3}$ & & & & \\
\hline & & GDP growth rate & $B_{4}$ & & & & \\
\hline \multirow{8}{*}{$\begin{array}{l}\text { Human activity } \\
\text { pressure }\end{array}$} & \multirow{8}{*}{$A_{3}$} & \multirow{5}{*}{$\begin{array}{l}\text { Land activity } \\
\text { pressure }\end{array}$} & \multirow{5}{*}{$B_{5}$} & \multirow{3}{*}{$\begin{array}{l}\text { Land-based } \\
\text { pollution }\end{array}$} & \multirow{3}{*}{$C_{1}$} & $\begin{array}{c}\text { Domestic wastewater discharge } \\
\text { volume }\end{array}$ & $D_{1}$ \\
\hline & & & & & & High and low aquaculture pond area & $D_{2}$ \\
\hline & & & & & & $\begin{array}{l}\text { Nitrogen and phosphorus content in } \\
\text { chemical fertilizers }\end{array}$ & $D_{a}$ \\
\hline & & & & Reclamation & $C_{2}$ & Area of cultivated land & $D_{4}$ \\
\hline & & & & $\begin{array}{c}\text { Animal } \\
\text { husbandry }\end{array}$ & $C_{\mathrm{a}}$ & $\begin{array}{c}\text { Total number of livestock at year } \\
\text { end }\end{array}$ & $D_{5}$ \\
\hline & & \multirow{3}{*}{$\begin{array}{l}\text { Marine activity } \\
\text { pressure }\end{array}$} & \multirow{3}{*}{$B_{7}$} & Mariculture & $C_{5}$ & Aquaculture raft farming area & $D_{6}$ \\
\hline & & & & Marine fishing & $C_{6}$ & Fixed fishing area & $D_{7}$ \\
\hline & & & & $\begin{array}{l}\text { Shipping } \\
\text { pollution }\end{array}$ & $C_{\mathrm{y}}$ & Number of fishing vessels & $D_{8}$ \\
\hline
\end{tabular}


Step ii: As the evaluation indicators are not unified (Tables 2 and 3), a differential method was used for standardization of the ecosystem pressure indicators $x_{i j}$ (Tables 4 and 5).

Table 2. Annual representative Xincun Lagoon ecosystem pressure values

\begin{tabular}{|c|c|c|c|c|c|}
\hline & 2011 & 2012 & 2013 & 2014 & 2015 \\
\hline Population density (people $/ \mathrm{km}^{2}$ ) & 586 & 600 & 590 & 574 & 558 \\
\hline Population growth rate $(\%)$ & 2.2 & 2.4 & 0 & 0 & 0 \\
\hline GDP per capita (RMB) & 20,378 & 26,775 & 30,472 & 34,000 & 36,857 \\
\hline GDP growth rate $(\%)$ & 6 & 8 & 13 & 8.5 & 8.4 \\
\hline Domestic wastewater discharge volume (tons) & $1,909,940$ & $1,889,292$ & $1,858,320$ & $1,806,700$ & $1,755,080$ \\
\hline High and low aquaculture pond area $\left(\mathrm{km}^{2}\right)$ & 5.879 & 6.542 & 7.667 & 7.667 & 7.667 \\
\hline Nitrogen and phosphorus content in chemical fertilizers $(\mathrm{kg})$ & 192,733 & 192,658 & 205,939 & 210,812 & 195,486 \\
\hline Area of cultivated land (hectares) & 5181 & 5179 & 5536 & 5667 & 5255 \\
\hline Total amount of livestock at year end (number of animals) & 19,245 & 21,458 & 18,565 & 19,982 & 20,382 \\
\hline Aquaculture raft farming area $\left(\mathrm{km}^{2}\right)$ & 2.489 & 2.632 & 2.769 & 2.836 & 3.219 \\
\hline Fixed fishing area $\left(\mathrm{km}^{2}\right)$ & 1.974 & 2.103 & 2.256 & 2.383 & 2.989 \\
\hline Total number of fishing vessels & 2257 & 2054 & 1896 & 1736 & 1932 \\
\hline
\end{tabular}

Data source description: the domestic wastewater discharge volume was calculated according to the sewage discharge coefficient method in the First Pollution Source Survey: Urban sub-volume. The aquaculture pond area, cultivated land area, aquaculture raft farming area, and fixed fishing area were based on satellite image analysis, and the rest of the data were obtained from the Lingshui Statistical Yearbook and the Hainan Statistical Yearbook

Table 3. Annual representative Li'an Lagoon ecosystem pressure values

\begin{tabular}{|c|c|c|c|c|c|}
\hline & 2011 & 2012 & 2013 & 2014 & 2015 \\
\hline Population density (people $/ \mathrm{km}^{2}$ ) & 397 & 406 & 408 & 467 & 443 \\
\hline Population growth rate $(\%)$ & 2.6 & 2.2 & 0.5 & 14.46 & 0 \\
\hline GDP per capita (RMB) & 8824 & 9253 & 9654 & 10,087 & 12,542 \\
\hline GDP growth rate $(\%)$ & 7 & 13.2 & 13 & 12.5 & 12 \\
\hline Domestic wastewater discharge volume (tons) & 877,540 & 898,188 & 903,350 & $1,032,400$ & 980,780 \\
\hline High and low aquaculture pond area $\left(\mathrm{km}^{2}\right)$ & 2.77 & 2.65 & 2.43 & 2.25 & 2.4 \\
\hline Nitrogen and phosphorus content in chemical fertilizers $(\mathrm{kg})$ & 38,948 & 38,390 & 37,014 & 36,716 & 16,330 \\
\hline Area of cultivated land (hectares) & 1047 & 1032 & 995 & 987 & 439 \\
\hline Total number of livestock at year end (number of animals) & 19,864 & 31,855 & 22,737 & 21,487 & 22,737 \\
\hline Aquaculture raft farming area $\left(\mathrm{km}^{2}\right)$ & 1.946 & 1.974 & 1.996 & 2.002 & 2.420 \\
\hline Fixed fishing area $\left(\mathrm{km}^{2}\right)$ & 0.41 & 0.45 & 0.49 & 0.53 & 0.83 \\
\hline Total number of fishing vessels & 325 & 300 & 335 & 312 & 335 \\
\hline
\end{tabular}

Data source description: the domestic wastewater discharge volume was calculated according to the sewage discharge coefficient method in the First Pollution Source Survey: Urban sub-volume. The aquaculture pond area, cultivated land area, aquaculture raft farming area, and fixed fishing area were based on satellite image analysis, and the rest of the data were obtained from the Lingshui Statistical Yearbook and the Hainan Statistical Yearbook 
Table 4. Annual representative Xincun Lagoon ecosystem pressure standardization values

\begin{tabular}{c|c|c|c|c|c}
\hline & $\mathbf{2 0 1 1}$ & $\mathbf{2 0 1 2}$ & $\mathbf{2 0 1 3}$ & $\mathbf{2 0 1 4}$ & $\mathbf{2 0 1 5}$ \\
\hline Population density (people/ $\left./ \mathrm{km}^{2}\right)$ & 0.51 & 0.52 & 0.51 & 0.50 & 0.48 \\
Population growth rate (\%) & 0.92 & 1.00 & 0.00 & 0.00 & 0.00 \\
GDP per capita (RMB) & 0.36 & 0.47 & 0.53 & 0.59 & 0.64 \\
GDP growth rate (\%) & 0.32 & 0.42 & 0.68 & 0.45 & 0.44 \\
Domestic wastewater discharge volume (tons) & 0.52 & 0.52 & 0.51 & 0.49 & 0.48 \\
High and low aquaculture pond area $\left(\mathrm{km}^{2}\right)$ & 0.43 & 0.48 & 0.57 & 0.56 & 0.57 \\
Nitrogen and phosphorus content in chemical fertilizers $(\mathrm{kg})$ & 0.48 & 0.48 & 0.51 & 0.52 & 0.48 \\
Area of cultivated land (hectares) & 0.48 & 0.48 & 0.51 & 0.52 & 0.48 \\
Total amount of livestock at year end (number of animals) & 0.48 & 0.54 & 0.46 & 0.50 & 0.51 \\
Aquaculture raft farming area (km $\left.{ }^{2}\right)$ & 0.44 & 0.46 & 0.49 & 0.50 & 0.56 \\
Fixed fishing area $\left(\mathrm{km}^{2}\right)$ & 0.40 & 0.42 & 0.45 & 0.48 & 0.60 \\
Total number of fishing vessels & 0.57 & 0.51 & 0.47 & 0.43 & 0.48 \\
\hline
\end{tabular}

Considering that the amount of evaluation indicators for ecosystem pressure assessment is generally large, the difference method was used to standardize the ecosystem pressure index. The specific calculation process is as described in Equations 1 and 2

Table 5. Annual representative Li'an Lagoon ecosystem pressure standardization values

\begin{tabular}{c|c|c|c|c|c}
\hline & $\mathbf{2 0 1 1}$ & $\mathbf{2 0 1 2}$ & $\mathbf{2 0 1 3}$ & $\mathbf{2 0 1 4}$ & $\mathbf{2 0 1 5}$ \\
\hline Population density $\left(\right.$ people/km $\left.{ }^{2}\right)$ & 0.46 & 0.47 & 0.47 & 0.54 & 0.51 \\
Population growth rate (\%) & 0.18 & 0.15 & 0.03 & 1.00 & 0.00 \\
GDP per capita (RMB) & 0.41 & 0.43 & 0.45 & 0.47 & 0.59 \\
GDP growth rate (\%) & 0.37 & 0.69 & 0.68 & 0.66 & 0.63 \\
Domestic wastewater discharge volume (tons) & 0.46 & 0.47 & 0.47 & 0.54 & 0.51 \\
High and low aquaculture pond area (km $\left.{ }^{2}\right)$ & 0.55 & 0.53 & 0.48 & 0.45 & 0.48 \\
Nitrogen and phosphorus content in chemical fertilizers (kg) & 0.70 & 0.69 & 0.67 & 0.66 & 0.30 \\
Area of cultivated land (hectares) & 0.70 & 0.69 & 0.67 & 0.66 & 0.30 \\
Total number of livestock at year end (number of animals) & 0.38 & 0.62 & 0.44 & 0.42 & 0.44 \\
Aquaculture raft farming area (km $\left.{ }^{2}\right)$ & 0.45 & 0.45 & 0.46 & 0.46 & 0.55 \\
Fixed fishing area (km $\left.{ }^{2}\right)$ & 0.33 & 0.36 & 0.40 & 0.43 & 0.67 \\
Total number of fishing vessels & 0.51 & 0.47 & 0.53 & 0.49 & 0.53 \\
\hline
\end{tabular}

Considering that the amount of evaluation indicators for ecosystem pressure assessment is generally large, the difference method was used to standardize the ecosystem pressure index. The specific calculation process is as described in Equations 1 and 2

The formula used for positive pressure indicators was (Eq. 1)

$$
x_{i j}^{\circ}=\frac{x_{i j}}{\max \left(x_{i j}\right)+\min \left(x_{i j}\right)^{*}}
$$

The formula used for negative pressure indicators was (Eq. 2)

$$
x_{i j}^{\circ}=1-\frac{x_{i j}}{\max \left(x_{i j}\right)+\min \left(x_{i j}\right)}
$$


Negative pressure is mainly targeted against economic pressure. This is because, under a specific environmental policy intervention, the overall environmental quality of a country or region will exhibit an initial deterioration followed by a subsequent improvement when economic strength increases.

Step iii: The analytic hierarchy process was used to determine weight values.

Step iv: Based on the determination of the weights (relative importance) at the corresponding layers of various single indicators and the total sorted weight (integrated importance) of the system layers, linear weighting was used to obtain the ecosystem pressure index further to evaluate pressure levels as follows (Eq. 3):

$$
E S I=\sum_{i=1}^{m} W_{i} X_{i}
$$

where ESI is the ecosystem pressure index; $W_{i}$ is the indicator weight; and $X_{i}$ is the standardized value of the indicator.

\section{Spatial quantitative assessment of the impact of human activities on lagoon ecosystem}

This study employed spatial quantization to investigate the relationship between human activities and marine ecosystems as described to evaluate the effects of human activities on the lagoon ecosystem and spatial visualization of the evaluation results was conducted ( $\mathrm{Li}$ et al., 2015). The specific evaluation process for the model was as follows: (i) Determination of the study site, including the spatial range and rational layout of unit points; (ii) Identification of seas with human activities, i.e. determination of effect points, including spatial positions, effect strength, and maximum effect distance; (iii) Calculation of the effects of various human activities on the lagoon ecosystem; (iv) Superimposition of the aforementioned processes in (3) (e.g., comprehensive evaluation).

Step i: The study site consisted of the maritime areas of Xincun and Li'an Lagoons. If human land activities were present, they were represented by unit points concentrated in the coastal region. Estimation results from papers above were used as data. The grid was divided into $100 \mathrm{~m} \times 100 \mathrm{~m}$ (Fig. 2).

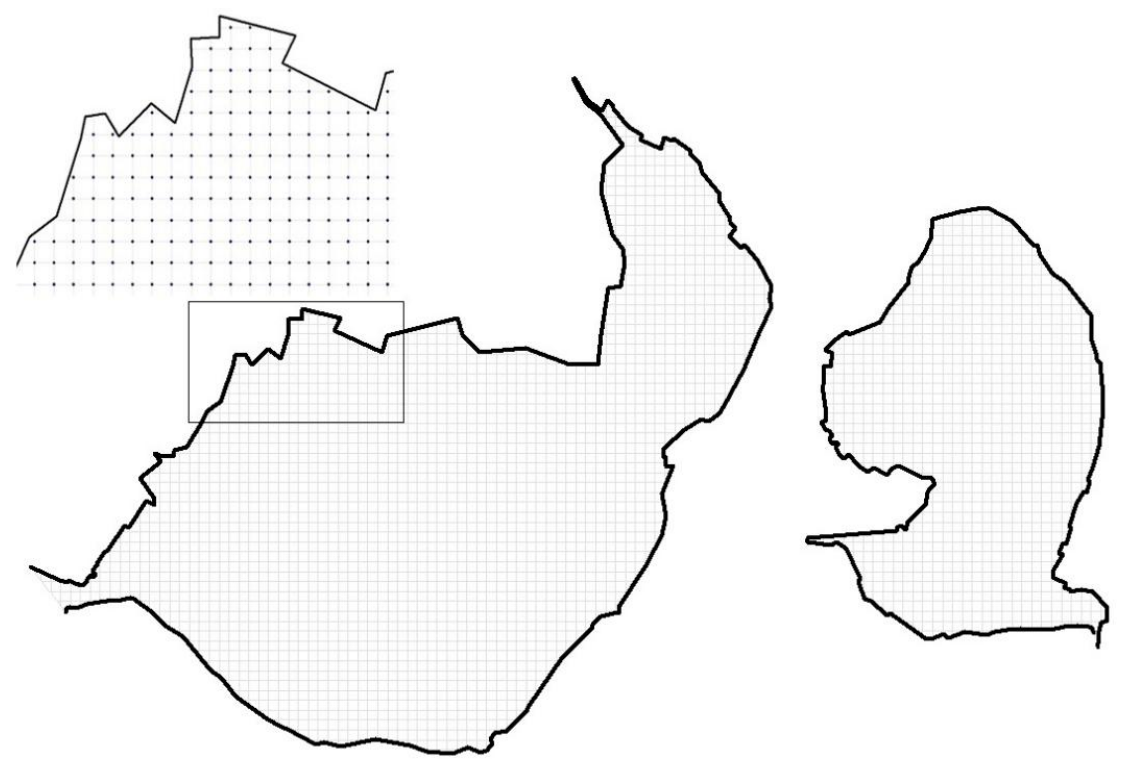

Figure 2. Map of study region and spatial unit points 
Step ii: In this study, eight human activities were selected according to the characteristics of the studied sea and actual utilization status to construct an evaluation indicator system that was subsequently used to summarize various seascape human activities comprehensively.

\section{A) Effect strength}

Effect strength was expressed from 0 to 1 , with 1 indicating the strongest impact and 0 indicating that the effect was negligible. The effect strength $(F)$ of various effect points of human activities was directly assigned values according to the grade of the actual survey value in the standard range (Halpern et al., 2008).

\section{B) Effect distance}

Parravicini (Parravicini et al., 2012) used a geospatial model to evaluate the pressure status of eight seascape human activities on marine ecosystems. Their results showed that the effect of each type of human activity on marine ecosystems was about $50 \%$. Therefore, this paper assumes that half the distance between any effect point and the furthest unit point is the maximum effective distance of that effect point (D).

\section{C) Indicator weight}

The indicator weights (W) of various human activities were determined according to the analytic hierarchy process. Table 6 shows the calculated weights.

Table 6. Evaluation indicator system and effect strength criteria for quantitative model

\begin{tabular}{|c|c|c|c|c|c|c|c|c|}
\hline \multirow[t]{2}{*}{ Target layer } & \multirow[t]{2}{*}{ Factor layer } & \multirow[t]{2}{*}{ Indicator layer } & \multicolumn{5}{|c|}{$\begin{array}{c}\text { Effect strength assigned value } \\
\text { table }\end{array}$} & \multirow{2}{*}{ Weight } \\
\hline & & & 1 & 0.75 & $<0.5$ & 0.25 & 0 & \\
\hline \multirow{8}{*}{$\begin{array}{l}\text { Impact of } \\
\text { human } \\
\text { activities on } \\
\text { marine } \\
\text { ecosystems }\end{array}$} & \multirow{5}{*}{$\begin{array}{l}\text { Land-based } \\
\text { human } \\
\text { activities }\end{array}$} & $\begin{array}{c}\text { Domestic wastewater } \\
\text { discharge volume }\left(10^{4} \text { tons }\right)\end{array}$ & $>5$ & $3-5$ & $1-3$ & $0-1$ & - & 0.1787 \\
\hline & & $\begin{array}{c}\text { High and low aquaculture } \\
\text { pond area }\left(\mathrm{km}^{2}\right)\end{array}$ & $>0.3$ & $0.15-0.3$ & $0.1-0.15$ & $0-0.1$ & - & 0.2148 \\
\hline & & $\begin{array}{l}\text { Nitrogen and phosphorus } \\
\text { content in chemical } \\
\text { fertilizers used (tons) }\end{array}$ & $>5$ & $3-5$ & $1-3$ & $0-1$ & - & 0.0837 \\
\hline & & $\begin{array}{c}\text { Area of cultivated land } \\
\text { (hectares) }\end{array}$ & $>30$ & $15-30$ & $5-15$ & $0-5$ & - & 0.0837 \\
\hline & & $\begin{array}{c}\text { Total number of livestock at } \\
\text { year end (number of } \\
\text { animals) }\end{array}$ & $>60$ & $40-60$ & $20-40$ & $0-20$ & - & 0.0837 \\
\hline & \multirow{3}{*}{$\begin{array}{l}\text { Marine human } \\
\text { activities }\end{array}$} & $\begin{array}{c}\text { Farming area of aquaculture } \\
\text { raft }\left(\mathrm{km}^{2}\right)\end{array}$ & $>0.6$ & $0.4-0.6$ & $0.2-0.4$ & $0-0.2$ & - & 0.2148 \\
\hline & & Fixed fishing area $\left(\mathrm{km}^{2}\right)$ & $>0.3$ & $0.2-0.3$ & $0.1-0.2$ & $0-0.1$ & - & 0.0481 \\
\hline & & $\begin{array}{c}\text { Total number of fishing } \\
\text { vessels }\end{array}$ & $>75$ & $50-75$ & $25-50$ & $0-25$ & & 0.0925 \\
\hline
\end{tabular}

Step iii: The formula for calculation of the effects of certain human activities on unit points was as follows (Eq. 4): 


$$
I=\sum_{i=1}^{m} F_{i} \times \frac{D_{i}-d_{i}}{D_{i}}
$$

In Equation 4, I represents the effects of a certain human activity on a unit point. Human activity is present in $m$ effect points; $i$ represents the $i$ th effect point; $F_{i}$ is the intensity of the $i$ th effect point of that human activity; $D_{i}$ is the maximum effect distance of the $i$ th effect point of that human activity; $d_{i}$ is the distance between the unit point and the $i$ th effect point of that human activity.

Step iv: The calculation formula for the integrated effects of various human activities on unit points was as follows (Eq. 5):

$$
I_{\text {Total }}=\sum_{j=1}^{n} I_{j} \times W_{j}
$$

where $I_{\text {Total }}$ represents the integrated effects of various human activities on that unit point and there are $n$ types of human activities; $j$ represents the $j$ th human activity; and $I_{j}$ is the effect of the jth human activity on the unit point. $W_{j}$ is the weight of the $j$ th human activity in the comprehensive evaluation.

\section{Results}

\section{Comprehensive assessment of lagoon ecosystem pressure}

\section{A) Xincun Lagoon}

Table 7 shows the ecosystem pressure composite values for Xincun Lagoon, which peaked in 2012 before gradually decreasing. This occurred because population pressure is gradually decreasing, during which time growth has been negative. Also, economic pressure has been stable since 2014. This is because, although GDP is growing, the growth rate is decreasing significantly. However, human activity pressure is increasing annually because, although the number of aquaculture ponds is generally unchanged (due to aquaculture pond management policies), the quantity and area of aquaculture rafts are increasing.

Table 7. Annual Xincun Lagoon ecosystem pressure composite values

\begin{tabular}{c|c|c|c|c|c}
\hline & $\mathbf{2 0 1 1}$ & $\mathbf{2 0 1 2}$ & $\mathbf{2 0 1 3}$ & $\mathbf{2 0 1 4}$ & $\mathbf{2 0 1 5}$ \\
\hline Pressure composite value & 0.492 & 0.533 & 0.476 & 0.459 & 0.472 \\
Population pressure & 0.142 & 0.152 & 0.051 & 0.050 & 0.048 \\
Economic pressure & 0.067 & 0.089 & 0.122 & 0.104 & 0.109 \\
Human activity pressure & 0.283 & 0.293 & 0.304 & 0.305 & 0.315 \\
\hline
\end{tabular}

Calculation explanation: On the basis of determining the weight (relative importance) of each individual indicator at its respective level and its total ranking weight (integrated importance) to the overall level of the system, the ecosystem pressure index can be further determined by the linear weighting method to evaluate the pressure level

\section{B) Li'an Lagoon}

Table 8 shows that the ecosystem pressure composite value for Li'an Lagoon increased continuously until 2014 . This occurred because population pressure showed a sudden increase in 2014 because it increased from 408 people in 2013 to 467 people. 
When compared with Xincun Lagoon, the GDP of Li' an Lagoon continued to increase, as did the rate of increase. Thus, economic pressure is still continuously increasing. However, human activity pressure started to decrease in 2012. Although the area of aquaculture rafts is increasing, and the area of high and low aquaculture ponds was generally unchanged (due to aquaculture pond management policies) the area of cultivated land shows an annual decreasing trend.

Table 8. Annual Li'an Lagoon ecosystem pressure composite values

\begin{tabular}{c|c|c|c|c|c}
\hline & $\mathbf{2 0 1 1}$ & $\mathbf{2 0 1 2}$ & $\mathbf{2 0 1 3}$ & $\mathbf{2 0 1 4}$ & $\mathbf{2 0 1 5}$ \\
\hline Pressure composite value & 0.448 & 0.489 & 0.466 & 0.569 & 0.462 \\
Population pressure & 0.064 & 0.062 & 0.051 & 0.154 & 0.051 \\
Economic pressure & 0.078 & 0.113 & 0.114 & 0.113 & 0.122 \\
Human activity pressure & 0.306 & 0.314 & 0.302 & 0.302 & 0.288 \\
\hline
\end{tabular}

Calculation explanation: On the basis of determining the weight (relative importance) of each individual indicator at its respective level and its total ranking weight (integrated importance) to the overall level of the system, the ecosystem pressure index can be further determined by the linear weighting method to evaluate the pressure level

\section{Cumulative impact intensity because of human activities}

Based on the research results of Halpern et al. (2008) and Li et al. (2015), we combine the actual situation of the research area to conduct research and analysis. For the specific calculation process, see Step i-Step iv of spatial quantitative assessment of the impact of human activities on lagoon ecosystem in the Methods section above.

Spatial data analysis of the effects of human activities on the Xincun and Li'an Lagoon ecosystems was conducted using the ArcGIS10.2 software, with Kriging interpolation employed to process the effect values of human activities. Figures 3 and 4 show the spatial quantitation results.

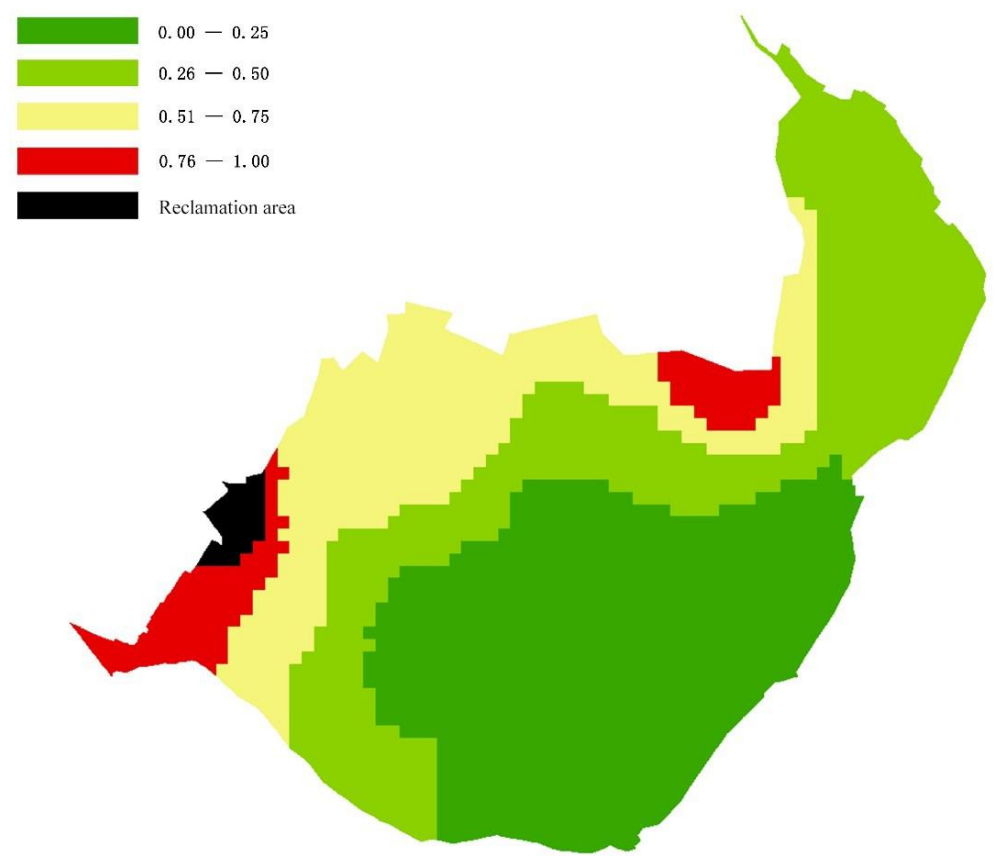

Figure 3. Map of cumulative impact intensity due to human activities in Xincun Lagoon 


$$
-6263-
$$
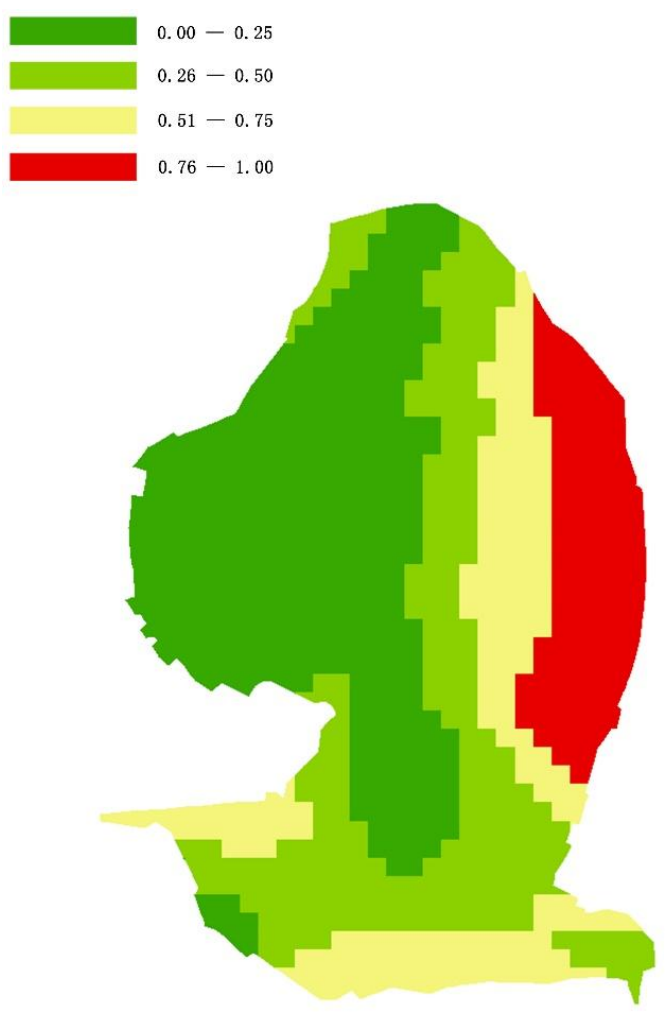

Figure 4. Map of cumulative impact intensity due to human activities in Li'an Lagoon

In Xincun Lagoon, extremely strong effect regions (effect values of 0.75-1.00) accounted for $6.67 \%$ of the entire sea space, while strong effect regions (effect values of $0.50-0.75$ ) accounted for $21.63 \%$ of the entire sea space; moderate effect regions (effect values of $0.25-0.50$ ) accounted for $32.32 \%$ of the entire sea space, and weak effect regions (effect values of $0.00-0.25$ ) accounted for $37.75 \%$ of the entire sea space. Also, some reclamation sites were located outside the managed coastline (black lines in the figure). As shown in Figure 3, the area with the strongest human activity in Xincun Lagoon is located at the mouth of the lagoon and around Tonghai Village inside the lagoon, while the human activity in the southern sea of the lagoon is almost negligible. Therefore, the effect value for that region is less than 0.25 .

In Li'an Lagoon, extremely strong effect regions (effect values of 0.75-1.00) accounted for $13.53 \%$ of the entire sea space; strong effect regions (effect values of $0.50-0.75$ ) accounted for $19.74 \%$ of the entire sea space; moderate effect regions (effect values of $0.25-0.50$ ) accounted for $26.75 \%$ of the entire sea space, and weak effect regions (effect values of $0.00-0.25$ ) accounted for $39.98 \%$ of the entire sea space. As shown in Figure 4, the area with the strongest human activity in Li'an Lagoon is located in Li'an Village. Conversely, the human activity in the western sea of the lagoon is almost negligible; therefore, the effect value for that region is less than 0.25 .

\section{Analysis of remediation measures}

According to the P-S-R model, after clarifying the pressure and status of Xincun and Li'an Lagoons, it will be necessary to combine the results of the studies above for analysis to effectively remediate the two lagoons. Generally, the response measures 
should be targeted against different aspects of pressure and status. Generally, the response measures should be targeted toward different aspects of pressure and status, as described below.

\section{Pressure reduction measures}

A) Optimization of aquaculture raft farming. The aquaculture capacity should be determined rationally. The specific measures are as follows. Aquaculture density should be controlled within the carrying capacity of the water body so that aquaculture pollutants do not exceed the self-cleaning capability of the water body. According to relevant studies (Hu et al., 2007), the presence of aquaculture raft farming causes the flow speed of some sea regions to significantly decrease, resulting in the reduced selfcleaning capability of the water body. Optimization of aquaculture raft layout should be conducted according to the unique hydrodynamic model of the study site. Adjustment and optimization of aquaculture structure should be conducted to develop the aquaculture of benthic economic species actively. Improvement of baitcasting techniques and improvement of feed quality will also greatly reduce water pollution.

B) Remediation of land-based pollution. According to the onsite survey and pollution calculations, domestic wastewater from the surrounding villages and towns of Xincun and Li'an Lagoons is an important source of land-based pollution. The specific measures to reduce this include the following. Sewage interception and treatment of domestic wastewater and solid waste of coastal villages and towns. Low aquaculture ponds, which are mariculture ponds that are below the surveyed coastline (State Oceanic Administration, 2012), not only occupy large amounts of valuable wetland but are usually accompanied by many mangrove forests. However, long-term immersion in aquaculture wastewater will threaten these habitats. Therefore, rapid pond reclamation and reforestation should be conducted to form a complete mangrove forest corridor. High aquaculture ponds are mariculture ponds that are above the surveyed coastline (State Oceanic Administration, 2012). Because it is difficult to remove these ponds completely, a wastewater treatment system of high aquaculture pond should be developed for centralized processing of the discharged wastewater.

\section{Ecological improvement measures}

A) Dismantlement of illegal facilities and garbage removal. The facilities to be dismantled and garbage to be removed include fixed fishing facilities and night-time fishing illumination equipment, utility poles that provide electricity for fishing and aquaculture rafts, and other fishing facilities that occupy and segment the sea. Also, floating public toilets and restaurants, as well as other fixed buildings that directly discharge excreta and solid waste into the sea should be removed. Finally, garbage thrown into the lagoons by tourists and villagers should be removed.

B) Sediment dredging. In the marine ecosystem, sediments are sinks and sources of nutrients, heavy metals, and persistent organic pollutants. Under conditions in which extrinsic pollutant sources are effectively controlled, biological or physical factors will promote the release of sediments. This can still result in maintenance of eutrophication in water bodies or deterioration of water quality for long periods of time. Sediment dredging can permanently remove contaminated sediment from aquatic systems and is widely used in the remediation of lakes, rivers, and bays (Zhong et al., 2007). 
C) Bottom culturing and release of shellfish. Relevant studies have shown that shellfish are commonly used for ecological restoration and remediation of water bodies. Shellfish can decrease the concentration of particulate organic matter (seaweeds and organic debris) in the water body, indirectly control the concentration of nitrogen and phosphorus salts, couple with the aquatic benthic environment, and protect biodiversity and create biological habitats. Also, shellfish play an important role in carbon fixation in the oceans. Specifically, shellfish can remove particulate carbon in the sea by filter feeding, absorb carbon during formation of calcium carbonate shells and sequester large amounts of marine carbon.

\section{Conclusion}

This study not only identifies the pressure categories of human activities on the lagoon but can also be used to determine the ecosystem pressure index; it is also possible to spatially quantify the cumulative impact intensity.

The calculation model introduced in the paper is suitable for coastal lagoons that are little affected by the outer seas, have relatively weak water exchange capacity, and have relatively flat seabed topography. The model not only quantifies the impact results to a value of $0-1$ in order to indicate the impact degree, but also displays the distribution of the impact results in the sea space. The findings can coordinate the entire research area for management but can also manage according to the different partitions of the affected areas in different regions.

The findings of this work allow us to draw the following conclusions:

(1) The results of the study showed that the intensity of human activities experienced by Xincun Lagoon decreased annually from 2011 to 2015 and the intensity of human activity was greatest at the mouth of the lagoon. Conversely, the intensity of human activities that Li'an Lagoon was subject to is still growing, although intensity was greatest at the Li'an town center.

(2) Generally, remediation measures are proposed based on pressure and state aspects. With regards to decreasing human activity pressure, optimization of aquaculture raft farming and remediation of land-based pollution are major methods proposed in the study. Also, dismantlement of illegal facilities and garbage removal, sediment dredging, bottom culturing and release of shellfish could improve the ecosystem status.

\section{REFERENCES}

[1] Ana, M. V., Angel, P. R., José, M. M., et al. (2018): Ecosystem services and main environmental risks in a coastal lagoon (MarMenor, Murcia, SE Spain). - Journal for Nature Conservation 43: 180-189.

[2] Bartelmus, P. (1999): Green accounting for a sustainable economy: Policy use and analysis of environmental accounts in the Philippines. - Ecological Economics 29(1): 155-170.

[3] Borja, A., Elliot, M., Andersen, J. H., et al. (2016): Overview of integrative assessment of marine systems: the ecosystem approach in practice. - Frontiers in Marine Science 3(55): $1-20$.

[4] Brown, M. T., Ulgiati, S. (1991): Energy-based indices and ratios to evaluate sustainability: monitoring economies and technology toward environmentally sound innovation. - Ecological Engineering 9(1-2): 51-69. 
[5] Château, P. A., Huang, Y. C. A., Chen, C. A., et al. (2015): Integrated assessment of sustainable marine cage culture through system dynamics modeling. - Ecological Modelling 299: 140-146.

[6] Cui, L. T., Li, Z. W. (2014): Assessment of ecological environment effects of coastal development in Hebei Province, China. - Chinese Journal of Applied Ecology 25(7): 2063-2070.

[7] Friends, A., Raport, D. (1979): Towards a Comprehensive Framework for Environment Statistics Stress-Response Approach. - Statistics Canada, Ottawa, Canada.

[8] Gundlach, E. R., Ruby, C. H., Hayes, M. O., et al. (1978): Theurquiola oil spill, La Coruña, Spain: impact and reaction on beaches and rocky coasts. - Environmental Geology 2(3): 131-143.

[9] Halpern, B. S., Walbridge S, Selkoe, K. A. et al. (2008): A global map f human impact on marine ecosystems. - Science 319(5865): 948-952.

[10] Hao C G, Shan W, G. (2012): Study on eco-environmental stress trend of Inner Mongolia based on ecological stress index. - Journal of Anhui Agricultural Sciences 40(15): 86848686.

[11] Hu, W. J., Yang, S. Y. (2007): The impact of mariculture on the marine ecosystem and studies on bioremediation. - Journal of Xiamen University (Natural Science) 8: 197-202.

[12] Leo, F. D., Miglietta, P. P., Pavlinović, S. (2014): Marine ecological footprint of Italian Mediterranean fisheries. - Sustainability 6(11): 7482-7495.

[13] Li, Y. F., Zhu, X. D., Zou, X. Q. et al. (2004): Resource-environmental pressure analysis and ecological cybernetics response: a case study of coastal wetlands in Yancheng, Jiangsu province. - Journal of Natural Resources 19(6): 754-760.

[14] Li, Y. F., Song, X. X., Wu, Z. X. et al. (2015): An integrated methodology for quantitative assessment on the impact of human activities on marine ecosystems: a case study in Laizhou Bay, China. - Oceanologia et Limnologia Sinica 1: 133-139.

[15] Marcotte, D., Hung, S. K., Caquard, S. (2015): Mapping cumulative impacts on Hong Kong's pink dolphin population. - Ocean \& Coastal Management 109: 51-63.

[16] Micheli, F., Halpern, B. S., Walbridge, S., et al. (2013): Cumulative human impacts on Mediterranean and black sea marine ecosystems: assessing current pressures and opportunities. - Plos One 8(12): e79889-e79889.

[17] Parravicini, V., Rovere, A., Vassallo, P. et al. (2012): Understanding relationships between conflicting human uses and coastal ecosystems status: A geospatial modelling approach. - Ecological Indicators 19: 253-263.

[18] Song, J., Wang, H. X., Liu, S. Y. (2014): Quantitative assessment of stress of economic development to environment using ecological stress index. - Chinese Journal of EcoAgriculture 22(3): 368-374.

[19] Wiegers, J. K., Feder, H. M., Mortensen, L. S., et al. (1998): A regional multiple-stressor rank-based ecological risk assessment for the fjord of Port Valdez, Alaska. - Human \& Ecological Risk Assessment An International Journal 4(5): 1125-1173.

[20] Xu F L, Zhao, S. S., Du, T. T., et al. (2004): Quantitative assessment for economic development stress status and trends of eco-environment. - China Population, Resources and Environment 14(4): 30-36.

[21] Xu, H. T., Zhou, L. F., Cheng, Q.(2017): Study on ecosystem health evaluation and risk assessment for Linghekou wetlands based on a PSR model. - Acta Ecologica Sinica 37(24): 8264-8274.

[22] Zhong, J. C., Fan, C. X. (2007): Advance in the study on the effectiveness and environmental impact of sediment dredging. - Journal of Lake Sciences 1: 1-10. 